\title{
Numerical simulation and optimizing of the hydrolysis reaction about methyl ethyl ketone azine
}

\author{
Weiwen Wang ${ }^{\star^{1,2}}$, a, Guojian Zhu ${ }^{1, b}$, Jihai Duan ${ }^{1,2, c}$, Zisheng Zhang ${ }^{\star^{1,2, d}}$ \\ ${ }^{1}$ College of Chemical Engineering, Qing University of Science and Technology \\ ${ }^{2}$ Ecological Chemical Base, Qingdao, P.R.China.266042 \\ awwwang@qust.edu.cn; ${ }^{b} t \mathrm{txs} .555 @ 163 . c o m ;{ }^{c}$ duanlihai@yahoo.com.cn; 'zhangzz77@@yahoo.com
}

Keywords:methyl ethyl ketone azine; catalytic reaction distillation; hydrolysis reaction; Aspen plus.

\begin{abstract}
The hydrolysis reaction of methyl ethyl ketone azine and the simulation of process are studied. The influence factors such as the plate number, the feed location, water and methyl ethyl ketone azine molar ratio and reflux ratio are studied respectively. The feeding method is single strand, reaction section number of the plates is 25 , feed position is 4 , water and methyl ethyl ketone azine molar ratio of 9 , the reflux ratio is 5 . At this point the conversion percent of MEK is $99.99 \%$; the mass fraction of tower reactor can reach $27.0 \%$.
\end{abstract}

\section{Introduction}

Hydrazine hydrate is widely used in the agricultural chemicals, foaming agent, pharmaceutical manufacturing [1] and water treatment, etc. In recent years, the hydrazine hydrate industry is rapid development, and the demand is increasing. Its application is limited by the high cost of production, so seeking economic and reasonable production technology is a focus in the study of hydrazine producers in a long time.

People have developed many preparation methods of hydrazine hydrate, such as Raschig process [2], Schestak of process [3], Bergbau-Bayer-Whiffen process [4], PCUK process [5, 6], and Air oxidation process [7]. PCUK process has the advantages of smaller investment, smaller environment pollution and lower cost. Air oxidation process is now at the experimental stage, and there is a certain distance away from the industrialization. In conclusion, the development of PCUK process has important significance to China's hydrazine hydrate production.

The intermediate of PCUK process is methyl ethyl ketone azine, and hydrolysis efficiency of methyl ethyl ketone azine is related to the quality and yield of hydrazine hydrate. This Hydrolysis reaction is reversible. In this article, the hydrolysis process of methyl ethyl ketone azine were studied, and using Aspen Plus simulated and optimized this progress to determine the optimum technological conditions through hydrolysis of butanone and get high yield of hydrazine hydrate.

\section{Hydrolytic process introductions}

The hydrolysis reaction about methyl ethyl ketone azine is a part of the production of hydrazine hydrate. The equation is as follows:

$$
\mathrm{R}_{1} \mathrm{R}_{2} \mathrm{C}=\mathrm{N}-\mathrm{N}=\mathrm{CR}_{2} \mathrm{R}_{1}+2 \mathrm{H}_{2} \mathrm{O} \rightarrow 2 \mathrm{R}_{1} \mathrm{R}_{2} \mathrm{C}=\mathrm{O}+\mathrm{N}_{2} \mathrm{H}_{4}
$$

Put the water and methyl ethyl ketone azine into the hydrolysis tower according to the certain proportion, under high temperature (140-180

-(C) Antaldressuddit(dns. Hydrazine hydrate and butanone are generated in the reaction. The reaction rectification has the advantages of low energy consumption and low pollution, so it has great technical advantages and development prospects. 


\section{Establishing mathematical model}

A. Assumptions of the model

In the process of simulation, based on the theory of equilibrium level module, this paper makes the following assumptions:

Operating in a stable state.

The reaction process mainly occurs in liquid phase. Reaction in the gas phase can be ignored.

The gas phase and liquid phase fully mixes at all of the equilibrium level.

The gas phase and liquid phase have reached equilibrium when it leaves the levels.

Ignore the heat of reaction.

The tower is adiabatic.

B. Mathematical model

a) The equilibrium level of material balance (M equation)

$$
q_{L, j-1} x_{i, j-1}+q_{V, j+1} y_{V, j+1}+q_{F i} z_{i, j}-q_{L, j} x_{i, j}-q_{V, j} y_{i, j}+V_{i} r_{i, j}=0 \quad(\mathrm{i}=1,2, \ldots, \quad \mathrm{C} ; \mathrm{j}=1,2, \ldots, \mathrm{N})
$$

b) Phase equilibrium equation (E equation)

$$
y_{i, j}-K_{i, j} x_{i, j}=0(\mathrm{i}=1,2, \cdots, C ; j=1,2, \cdots, N) K_{i, j}=\gamma_{i, j} \cdot \phi_{i, j}^{s} \cdot p_{i, j}^{s} \times \exp \left[V_{m, i, j}^{L} \cdot\left(P-P_{i, j}^{s}\right) /\left(R T_{j}\right)\right] /\left(\hat{\phi}_{i, j} p_{i}\right)
$$

c) Normalization method (S equation)

$$
\begin{aligned}
& \sum_{i=1}^{c} x_{i, j}-1.0=0 \quad(\mathrm{i}=1,2, \ldots, \quad \mathrm{C} ; \mathrm{j}=1,2, \ldots, \mathrm{N}) \\
& \sum_{i=1}^{c} y_{i, j}-1.0=0 \quad(\mathrm{i}=1,2, \ldots, \quad \mathrm{C} ; \mathrm{j}=1,2, \ldots, \mathrm{N})
\end{aligned}
$$

d) Enthalpy change scale formula (H equation)

$$
q_{L, j-1} H_{j+1}^{L}+q_{V, j+1} H_{j+1}^{V}+q_{F, j} H_{F+1}^{F}-q_{j} H_{j}^{V}-Q_{j}=0 \quad(\mathrm{i}=1,2, \ldots, \mathrm{C} ; \mathrm{j}=1,2, \ldots, \mathrm{N})
$$

C. The choice of physical methods

NRTL equation can be used binary data to calculate the properties of complex solution. The prominent advantage is NRTL equation which is suitable for non ideal strong liquid, also applies to the miscibility and part of the miscibility of the system. The results of the use of NRTL equation is been proved to be ideal by practice. So the system in this paper is calculated and simulated by using NRTL equation.

D. Choose dynamics equations

The total reaction rate of the reversible reaction can be expressed as the type (7):

$$
\mathrm{r}_{A}=-d C_{A} / d t=k_{+} C_{A}^{a} C_{B}^{b}-k_{-} C_{C}^{c} C_{D}^{d}
$$

It was used least squares method for nonlinear programming and homogeneous reversible reaction dynamics model to obtain the dynamics equation [8]. Get the following comparative perfect dynamics equations [9-10]:

The distillation kinetics equation

$$
r_{A}=-\frac{d_{C_{A}}}{d_{C_{B}}}=1.200 \mathrm{e}^{-\frac{2434.8}{\mathrm{RT}}} C_{A}^{1.5811} C_{B}^{0.4741}-0.042 e^{-\frac{341.2}{R T}} C_{C}^{0.3458} C_{D}^{0.2643}
$$

(2) The catalytic distillation kinetics equation (Complexation cation exchange resin D152)

$$
r_{A}=-\frac{d_{C_{A}}}{d_{C_{B}}}
$$

$$
\begin{aligned}
& =4.676 \mathrm{e}^{-\frac{2213.7}{\mathrm{RT}}} C_{A}^{0.1049} C_{B}^{0.1108} \\
& -4.348 e^{-\frac{120.81}{R T}} C_{C}^{0.1186} C_{D}^{0.1243}
\end{aligned}
$$




\section{The simulation results and analysis}

A.The choice of the Aspen module

This article selected the RadFrac rectification module, and discussed the operating conditions of reaction rectifying column. Through researching literature, sensitivity analysis and adjusting the parameters, get the simulation results of the optimal.

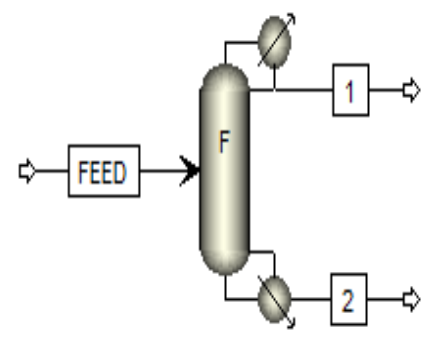

Figure1. Aspen reaction distillation module

The reaction distillation and catalytic reaction distillation

Table 1 The reaction distillation and catalytic reaction distillation

\begin{tabular}{|c|c|c|c|c|c|c|}
\hline & \multicolumn{3}{|c|}{ The top product quality/Kg } & \multicolumn{3}{c|}{ The bottom product quality/Kg } \\
\hline & $\begin{array}{c}\text { Methyl ethyl } \\
\text { ketone azine }\end{array}$ & $\begin{array}{c}\text { Hydraz } \\
\text { ine }\end{array}$ & $\begin{array}{c}\text { Buta } \\
\text { none }\end{array}$ & $\begin{array}{c}\text { Methyl } \\
\text { ethyl } \\
\text { ketone } \\
\text { azine }\end{array}$ & $\begin{array}{c}\text { Hydra } \\
\text { zine }\end{array}$ & Butanone \\
\hline RD & 2.423 & 0.062 & $\begin{array}{c}5837 . \\
582\end{array}$ & 38.751 & $\begin{array}{c}1297 . \\
238\end{array}$ & 0.678 \\
\hline CRD & 0.299 & 0.006 & $\begin{array}{c}5879 . \\
804\end{array}$ & 0.458 & $\begin{array}{c}1306 . \\
530\end{array}$ & 0.025 \\
\hline
\end{tabular}

It can be seen from table 1 that the conversion rate of methyl ethyl ketone azine in catalytic reaction distillation is higher. At the same time, the yield of hydrazine is relatively higher.

B.The optimization of catalytic reaction distillation conditions

The sensitivity analysis situation is shown in the following figures.

1) The plate number as the independent variable did sensitivity analysis. As shown in figure 2. Considering the industrial cost and simple practical, the plate number of the tower was set to 25 pieces.

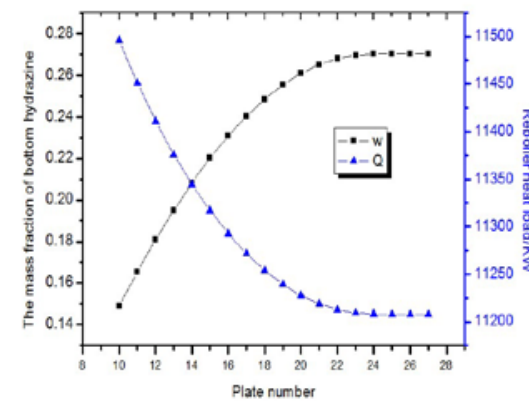

Figure2. The plate number sensitivity analysis

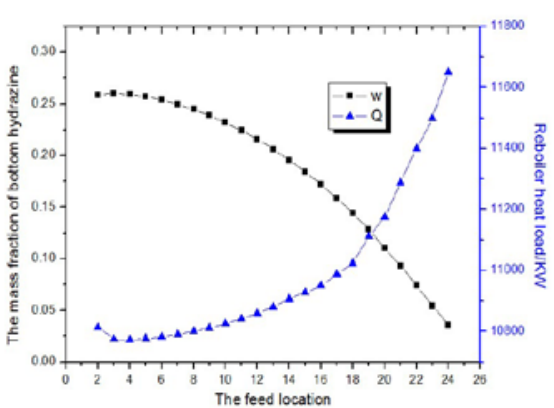

Figure3. The feed location sensitivity analysis

The feed position as the independent variable did sensitivity analysis. As shown in figure 3.Chosen the feed position is 4 .

The $n(\mathrm{H} 2 \mathrm{O})$ : $\mathrm{n}(\mathrm{C} 8 \mathrm{H} 16 \mathrm{~N} 2)$ as the independent variable did sensitivity analysis. As shown in figure 4. Chosen the $\mathrm{n}(\mathrm{H} 2 \mathrm{O}): \mathrm{n}(\mathrm{C} 8 \mathrm{H} 16 \mathrm{~N} 2)=9$. 

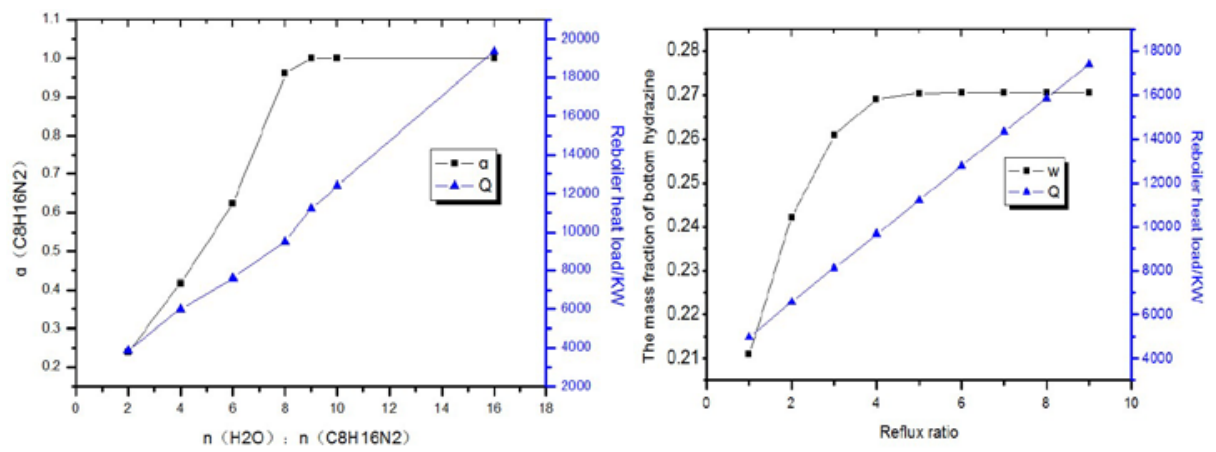

Figure4. The $\mathrm{n}(\mathrm{H} 2 \mathrm{O})$ : $\mathrm{n}(\mathrm{C} 8 \mathrm{H} 16 \mathrm{~N} 2)$ sensitivity analysis Figure5. The reflux ratio sensitivity analysis

The reflux ratio as the independent variable did sensitivity analysis. As shown in figure 5.Chosen the reflux ratio is 5 .

C.Results contrast

The experimental results, the simulation results of the literature [12] and the simulation results of this paper were compared. The result is in the following table:

Table 2 The result contras

\begin{tabular}{|c|c|c|c|}
\hline & $\begin{array}{c}\mathrm{n}(\mathrm{H} 2 \mathrm{O}): \\
\mathrm{n}(\mathrm{C} 8 \mathrm{H} 16 \mathrm{~N} \\
2)\end{array}$ & $\begin{array}{c}\mathrm{a} \\
(\mathrm{C} 8 \mathrm{H} 16 \mathrm{~N} \\
2) / \%\end{array}$ & $\mathrm{w}(\mathrm{N} 2 \mathrm{H} 4) / \%$ \\
\hline $\begin{array}{c}\text { experimental } \\
\text { value }\end{array}$ & 30 & 25.91 & 7.54 \\
\hline $\begin{array}{c}\text { Literature } \\
\text { simulation value }\end{array}$ & 9.5 & 99.84 & 20.40 \\
\hline $\begin{array}{c}\text { This paper } \\
\text { simulation value }\end{array}$ & 9 & 99.99 & 27.00 \\
\hline
\end{tabular}

\section{Conclusion}

Selecting rational catalyst is very important in the reaction distillation. The use of the catalyst can not only reduce the reaction time, also can increase the methyl ethyl ketone azine conversion rate. The reaction rectification tower model of this paper, theoretical plate number is 25 , feed position is 4, n (H2O): $\mathrm{n}(\mathrm{C} 8 \mathrm{H} 16 \mathrm{~N} 2)=9$, conversion rate of methyl ethyl ketone azine was 99.99\%, and the tower kettle hydrazine mass fraction is $27.0 \%$.

\section{Acknowledgements}

This work was supported by the National Natural Science Foundation of China (21276132) and the Livelihood Project Foundation of Qingdao (13-1-3-128-nsh).

\section{References}

[1] Tao JJ. The applications of hydrazine hydrate [J]. Chinese chloralkali, 2006, (11): 30 - 33.

[2] Rasching. Process for the preparation of concentrated solutions of hydrazine hydrates [P]. US910858. 1919. 03.10

[3] Wu DK, Xu JG, Sun YG etc. Optimizations of urea production of hydrazine hydrate technology. [P]. CN1110272. 1995. 10.18

[4] Rudolf Mundi. Process for the production of hydrazine hydrate [P].US3077383.1963.02.12

[5] Kirk-othmer. Hydrazine and its derivatives [M]. New York: John Wiley\&Sons.1980 (12): 734-771.

[6] Powell R. Hydrazine and its derivatives [J]. Chemical Process Review Series. 1968(28): 145160.

[7] Hiromu Hayashi. Process of hydraze synthesis [J]. Applied Catalysis. 1988(11): 213-216.

[8] Zhu BC. Reaction engineering [M]. Beijing: Chemical industry press, 2007.

[9] Wang T. Hydrogen peroxide preparation process of hydrazine hydrate research [D]. Shanghai: 
East China University of science and technology, 2007.

[10] Lin JD. Study on proceeding of catalytic distillation hydrolysis of methyl ethyl ketone azine [D]. Tianjin: Hebei University of technology, 2013. 